OPEN ACCESS

Edited by:

Mohamed A. Yassin,

Hamad Medical Corporation, Qatar

Reviewed by:

Yasser Wali,

Sultan Qaboos University, Oman

Heather Leitch,

St. Paul's Hospital, Canada

Mervat Mattar

Cairo University, Egypt

*Correspondence:

Giuseppe A. Palumbo

palumbo.ga@gmail.com

Specialty section:

This article was submitted to

Hematologic Malignancies,

a section of the journal

Frontiers in Oncology

Received: 02 August 2021

Accepted: 08 September 2021

Published: 06 October 2021

Citation:

Palumbo GA, Galimberti S,

Barcellini W, Cilloni D, Di Renzo N, Elli EM, Finelli C, Maurillo L, Ricco A, Musto $P$, Russo $R$ and Latagliata $R$ (2021) From Biology to

Clinical Practice: Iron Chelation

Therapy With Deferasirox.

Front. Oncol. 11:752192.

doi: 10.3389/fonc.2021.752192

\title{
From Biology to Clinical Practice: Iron Chelation Therapy With Deferasirox
}

\begin{abstract}
Giuseppe A. Palumbo ${ }^{1 *}$, Sara Galimberti ${ }^{2}$, Wilma Barcellini ${ }^{3}$, Daniela Cilloni ${ }^{4}$, Nicola Di Renzo ${ }^{5}$, Elena Maria Elli ${ }^{6}$, Carlo Finelli ${ }^{7}$, Luca Maurillo $^{8}$, Alessandra Ricco ${ }^{9}$, Pellegrino Musto ${ }^{9,10}$, Rodolfo Russo ${ }^{11}$ and Roberto Latagliata ${ }^{12}$

${ }^{1}$ Department of Scienze Mediche Chirurgiche e Tecnologie Avanzate "G.F. Ingrassia," University of Catania, Catania, Italy, 2 Section of Hematology, Department of Clinical and Experimental Medicine, University of Pisa, Pisa, Italy, ${ }^{3}$ Hematology, Fondazione Istituto di Ricovero e Cura a Carattere Scientifico (IRCCS) Ca' Granda Ospedale Maggiore Policlinico di Milano and University of Milan, Milan, Italy, ${ }^{4}$ Department of Clinical and Biological Sciences, University of Turin, Turin, Italy, ${ }^{5}$ Hematology and Transplant Unit, Ospedale Vito Fazzi, Lecce, Italy, ${ }^{6}$ Division of Hematology and Bone Marrow Unit, Ospedale San Gerardo, Aziende Socio Sanitarie Territoriali (ASST), Monza, Italy, ${ }^{7}$ IRCCS Azienda Ospedaliero-Universitaria di Bologna, Istituto di Ematologia "Seràgnoli", Bologna, Italy, ${ }^{8}$ Department of Onco-hematology, Fondazione Policlinico Tor Vergata, Rome, Italy, ${ }^{9}$ Unit of Hematology and Stem Cell Transplantation, Azienda Ospedaliera Universitaria (AOU) Consorziale Policlinico, Bari, Italy, ${ }^{10}$ Department of Emergency and Organ Transplantation, "Aldo Moro" University School of Medicine, Bari, Italy, ${ }^{11}$ Clinica Nefrologica, Dialisi e Trapianto, Department of Integrated Medicine with the Territory, IRCCS Ospedale Policlinico San Martino, Genoa, Italy, ${ }^{12}$ Unità Operativa Complessa (UOC) Ematologia, Ospedale Belcolle, Viterbo and Division of Cellular Biotechnology and Hematology, Sapienza University, Rome, Italy
\end{abstract}

Iron chelation therapy (ICT) has become a mainstay in heavily transfused hematological patients, with the aim to reduce iron overload (IOL) and prevent organ damage. This therapeutic approach is already widely used in thalassemic patients and in low-risk Myelodysplastic Syndrome (MDS) patients. More recently, ICT has been proposed for high-risk MDS, especially when an allogeneic bone marrow transplantation has been planned. Furthermore, other hematological and hereditary disorders, characterized by considerable transfusion support to manage anemia, could benefit from this therapy. Meanwhile, data accumulated on how iron toxicity could exacerbate anemia and other clinical comorbidities due to oxidative stress radical oxygen species (ROS) mediated by free iron species. Taking all into consideration, together with the availability of approved oral iron chelators, we envision a larger use of ICT in the near future. The aim of this review is to better identify those non-thalassemic patients who can benefit from ICT and give practical tips for management of this therapeutic strategy.

Keywords: iron chelation therapy (ICT), deferasirox, myelodysplastic syndromes (MDS), myelofibrosis (MF), radical oxygen species (ROS), iron toxicity, anemia

\section{INTRODUCTION}

Iron chelation therapy (ICT) has become a mainstay in heavily transfused hematological patients, with the aim to reduce iron overload (IOL) and prevent organ damage. International and Italian guidelines recommend ICT in low-risk Myelodysplastic Syndrome (MDS) patients (1). ICT should also be considered for transfusion-dependent patients with high-risk disease, when they are 
responding to therapies able to modify their life expectancy or if they are candidate for an allogeneic stem cell transplantation (HSCT) in their therapeutic program $(2,3)$.

Considering hematological and hereditary disorders, characterized by considerable transfusion support to manage anemia, consequent iron toxicity contributes to exacerbate anemia and other clinical comorbidities due to oxidative stress radical oxygen species (ROS) mediated by free iron species. Therefore, ICT has been introduced in the last years also in these additional categories of patients recognizing the importance of this therapy beyond the supportive aim, to counteract iron toxicity itself.

Approved iron chelators in the abovementioned diseases are deferoxamine (subcutaneous route) and deferasirox (oral administration). Unlike thalassemic patients, in whom it should be continued indefinitely, in patients with MDS and other hematological conditions, ICT can usually be continued until resolution of transfusion dependency and/or normalization of iron toxicity available markers (4-8).

\section{THE CURRENT ROLE OF IRON CHELATION THERAPY IN MYELODYSPLASTIC SYNDROMES}

\section{Why to Use ICT in Patients With MDS? Mechanisms That Can Favor Iron Toxicity in Patients With MDS}

MDSs belong to a family of clonal dysfunctions of the hematopoietic system, which result in failure of bone marrow hematopoiesis (ineffective hematopoiesis) and in an increased risk of progression to acute myeloid leukemia (AML). A common complication observed in these anemic patients is iron toxicity, which not only causes organ damage in liver, heart, and endocrine glands but also has toxic effects on the bone marrow niche, favoring ineffective hematopoiesis, genomic instability, and eventual clonal evolution towards acute leukemia, with consequent negative implications for survival and quality of life $(9,10)$.

Dyserythropoiesis affects the regulation of iron homeostasis, favoring increased intestinal absorption and plasma recirculation. In this setting, the two key factors involved in the mechanisms triggered by ineffective erythropoiesis are

- hepcidin, whose generally decreased levels vary in the different forms of MDS, with lower values observed in lower-risk MDS and higher values in higher-risk MDS and in chronic myelomonocytic leukemia (CMML) (11)

- hypoxia, which increases the expression of DMT1, DCYTB, and FPN in the enterocytes, the epithelial cells that form the epithelial lining of the intestinal villi, resulting in increased intestinal iron absorption (12).

These pathological iron load mechanisms are active regardless of the need for transfusions, although transfusion support considerably worsens this pre-existing overload $(9,13-15)$.
Indeed, each unit of packed red cells contains 200-250 mg of iron (approximately 100 times the normal daily intake). Moreover, at diagnosis $80 \%$ of patients with MDS present already anemia due to ineffective erythropoiesis and requiring blood transfusions (16-18). Consequently, it is very common that chronic transfusiondependent patients will develop IOL.

\section{Definition of a Genetic Profile Predisposing for Iron Overload}

Different gene mutations and/or alterations that have a direct effect on iron metabolism and accumulation have been reported in certain forms of MDS. These include the following:

- SF3B1 mutations: these mutations, frequently observed in MDS patients and especially when ring sideroblasts (RS) are present, dysregulate the RNA splicing of the erythroid transcription factors TAL1 and GATA1, resulting in increased but ineffective erythropoiesis (19). SF3B1-mutated patients present mitochondrial iron accumulation (20) and increased expression of a specific isoform of SLC25A37 (an important transporter of $\mathrm{Fe}(2+)$ into the mitochondria) (21). Splicing alterations have been observed in the key genes associated with iron accumulation.

- 5q deletion: this karyotypic alteration results in considerable ineffective erythropoiesis associated with the heterozygous deletion of RPS14. RPS14 haploinsufficiency activates the innate immune system and increases the expression of S100A8-S100A9, resulting in p53-dependent erythroid differentiation defects (22).

- TET2 mutations: (only in a subset of patients with MDS) may be involved in iron metabolism and in heme biosynthesis in the erythroblasts. Studies using TET2 knockdown mouse models have shown high serum and mitochondrial ferritin levels and dysregulation in a number of genes involved in iron metabolism (23).

\section{Diagnostic Workup for Iron Toxicity in Patients With MDS}

The approaches currently employed to diagnose iron overload include

- estimate iron intake following transfusions;

- serum ferritin and transferrin saturation measurements (blood ferritin levels must be monitored monthly, whereas follow-up monitoring of the parameter trends should be performed every 3-6 months);

- magnetic resonance imaging (MRI) of liver, pancreas and heart evaluation when available

- morphological evaluation of bone marrow iron by Perls staining.

Serum ferritin is an indirect and unreliable measurement of the entity of iron deposits in the body; although there is no validated threshold, as for other conditions such as thalassemia, 
experts consider a ferritin level $>1,000 \mathrm{ng} / \mathrm{ml}$ to be suggestive of IOL and suggest serial/periodic evaluation of ferritin to evaluate trends instead of absolute values. However, as high ferritin levels may be secondary to an inflammatory state regardless of iron burden, it is always advisable to assess ferritin trends and transferrin saturation suggesting the presence of unbound iron that is harmful for several organs (24).

Transferrin saturation values $>60-70 \%$ are correlated with free iron in plasma as non-transferrin-bound iron (NTBI) $(5,25-$ 27). A subcomponent of NTBI, called labile plasma iron (LPI), is a potent redox-active form capable of permeating cells through free cellular ionic channels, inducing enlargement of the amount of labile cellular iron (LCI) that in turns leads to increased levels of intracellular ROS. The consequent intracellular oxidative stress condition cause iron-related cellular damages or even cellular death (10).

Unfortunately, at the time being, measurements of NTBI and LPI are not yet standardized methods, available only in selected research laboratories.

\section{Lower-Risk MDS Patients: How and When to Chelate \\ When to Start Iron Chelation Therapy}

Current guidelines (SIE, ELN, NCCN) $(2,28,29)$ consider the following parameters as criteria for the initiation of ICT in patients with lower-risk MDS:

- Transfusion dependency (with transfusion burden of at least 20 units of packed red cells).

- Ferritin level $>1,000 \mathrm{ng} / \mathrm{ml}$.

- Life expectancy $>12-24$ months.

- When the chosen drug is deferasirox, $\mathrm{CrCl}$ has to be $>60 \mathrm{ml} /$ min; the starting dose of deferasirox is usually $7 \mathrm{mg} / \mathrm{kg}$ for the new formulation.

Evidence of oxidative stress due to iron-induced ROS before the conventional limit of 20 transfused units might lead to review current indications for early starting ICT providing a better tolerated lower-dose treatment (for deferasirox, $3.5 \mathrm{mg} / \mathrm{kg}$ ) for reducing iron overload and thus ROS overproduction promptly (1).

Hence, it is under discussion the ideal approach to candidate patients which might lead to an expansion of the indications for ICT, including the following:

- Patients with transfusion-dependent MDS (and bone marrow failure in general), regardless of the International Prognostic Scoring System (IPSS) risk level, taking into consideration the presumable life expectancy

- Patients with a transfusion history (even if recently started) and/or ferritin $\geq 500 \mathrm{ng} / \mathrm{ml}$, in the absence of hepatocellular necrosis and/or inflammation

\section{When to Discontinue Iron Chelation Therapy}

Although there is currently a divergent opinion on the optimal duration of ICT, some guidelines (NCCN, ELN) $(28,29)$ recommend considering therapy interruption when serum ferritin levels are $<1,000 \mathrm{ng} / \mathrm{ml}$ (whereas in the $\mathrm{SmPc}$ for deferasirox, the threshold value is $<500 \mathrm{ng} / \mathrm{ml}$ ). A consensus statement issued by the MDS Foundation Working Group in 2008 suggests continuing therapy for the entire duration of transfusion need (1). With the aim to prevent damage induced by free toxic iron exposure rather than iron bulk, it might be useful to consider not only ferritin values but also transferrin saturation, when considering the possibility of discontinuing the chelation treatment. Although the threshold value of transferrin saturation that protects from organ damage is not yet known, the iron chelation optimal goal should be a normal transferrin saturation value. Finally, when ferritin levels during deferasirox therapy goes below $300 \mu \mathrm{g} / \mathrm{L}$, a temporary discontinuation should be taken into consideration for a potential toxicity increase of chelation therapy itself.

\section{Clinical Outcomes and Iron Chelation With Deferasirox in Lower-Risk MDS}

In Table 1, response to chelation treatment, rate of discontinuation, and erythroid response observed in the main studies with DFX in MDS low-risk setting are reported.

\section{Possible Effects of Iron Chelation in Addition to the Decrease in Iron Overload}

In MDS patients, when assessing iron-induced damage, changes in the dynamic equilibrium between functional iron pool and deposited iron pool must be considered in addition to tissue iron concentrations.

This deposition results in exposure to iron, which causes organ damage mainly to the heart, blood vessels, and bone marrow, a worsening hematopoiesis, and an enhanced clonal instability.

In MDS, further clinical outcomes are observed during chelation treatment with deferasirox, such as the following:

- Overall survival (OS). A number of retrospective studies show that chelated MDS patients have a better median survival than those who are not chelated. This finding was subsequently confirmed by a meta-analysis (eight studies for a total of 1,562 patients), which reported an advantage in terms of survival greater than 61.2 months (38). Although these observations may be partly attributed to selected bias, the finding of a positive effect of ICT on the OS of patients with MDS would appear to be fairly consistent. In addition, a Canadian prospective study that collected data from March 2006 to July 2016 demonstrated the advantage in terms of survival in patients with MDS receiving ICT independently by confounding factors such as age, comorbidities, the Revised International Prognostic Scoring System (R-IPSS), and treatment with disease-modifying drugs (39). An improvement in OS for ICT patients was also evidenced in a propensity-score analysis on transfused lower-risk MDS subjects in the European MDS Registry (40).

In addition to an increase in OS (133 versus 105 months; $\mathrm{p}=0.009$ ), the IRON2 retrospective study reported a significant increase in cardiac event-free survival (EFS) in the 146 patients who received ICT (of whom $72 \%$ treated with 
TABLE 1 | Response to chelation treatment, rate of discontinuation, and erythroid response in the main studies with deferasirox in MDS low-risk setting.

\begin{tabular}{|c|c|c|c|c|c|c|c|}
\hline & $\mathbf{N}^{\circ}$ Pts & $\begin{array}{c}\text { Dosage } \\
\text { (mg/kg/day) }\end{array}$ & $\begin{array}{l}\text { Ferritin at baseline, } \\
\text { ng/ml (median) }\end{array}$ & $\begin{array}{c}\text { Ferritin at } 12^{\text {th }} \text { month, } \\
\mathrm{ng} / \mathrm{ml} \text { (median) }\end{array}$ & $p$ & $\begin{array}{l}\% \text { stop DFX at } \\
12^{\text {th }} \text { month }\end{array}$ & $\begin{array}{c}\text { Erythroid } \\
\text { response (\%) }\end{array}$ \\
\hline EPIC (30) & 341 & $10-30$ & 2,730 & 1,904 & 0.002 & 48.7 & 22.6 \\
\hline GIMEMA & 152 & $10-20$ & 1,966 & 1,475 & $<0.0001$ & 55.2 & 15.5 \\
\hline \multicolumn{8}{|l|}{ MDS0306 (31) } \\
\hline GERMAN & 50 & 20-30 & 2,447 & 1,685 & 0.01 & 52.0 & 11.0 \\
\hline \multicolumn{8}{|l|}{ STUDY (32) } \\
\hline US & 176 & 20 & 2,771 & 2,210 & $<0.001$ & 47.0 & 15.0 \\
\hline \multicolumn{8}{|l|}{ STUDY (33) } \\
\hline Hematology & 40 & $10-30$ & 2,878 & 1,400 & $<0.001$ & 40.0 & 10.0 \\
\hline \multicolumn{8}{|l|}{ Sapienza (34) } \\
\hline $\begin{array}{l}\text { GROM + } \\
\text { Basilicata (35) }\end{array}$ & 118 & $10-20$ & 1,773 & 1,300 & $<0.001$ & 35.0 & 19.0 \\
\hline GRUPPO & 55 & $10-30$ & 2,362 & 683 & 0.001 & $N R$ & 29 \\
\hline \multicolumn{8}{|l|}{ CAMPANO (36) } \\
\hline STUDY & 123 & $10-20$ & 2,679 & 2,000 & 0.0002 & 37.7 & NR \\
\hline \multicolumn{8}{|l|}{ EXTEND (37) } \\
\hline STUDY & 44 & $10-30$ & 2,442 & 2,077 & 0.06 & 29.5 & NR \\
\hline EXJANGE (37) & & & & & & & \\
\hline
\end{tabular}

deferasirox) compared to those who did not (137 versus 90 months; $\mathrm{p}=0.004)$ (41).

Focusing on the clinical outcomes, the results of the TELESTO randomized, double-blind prospective study, which evaluated the effects of treatment with deferasirox versus placebo in patients with low-/int-1-risk MDS have been reported. The primary endpoint of the study was EFS: of a total of 225 randomized patients, the group treated with deferasirox showed a median EFS (time to the first adverse event, constituted by clinically significant organ toxicity, including cardiac and hepatic events, evolution to leukemia or death) that was significantly longer than that observed in the placebo arm (1,440 vs.1,091 days; risk reduction: 36.4; $\mathrm{p}=0.015$ ) (Figure 1). The use of this molecule is therefore supported in patients with low-/int-1-risk MDS with iron overload (42).
- Evolution to acute leukemia. Regarding the risk of evolution to leukemia, data are still controversial: preclinical models describe the effect of ICT to reduce genetic instability induced by the greater production of ROS. Indeed, a significant reduction in leukemia-free survival (LFS) has been reported in patients with transfusion-dependent disease $(41,43)$. The American US22 registry data on 600 patients with transfusion-dependent low-risk MDS [of whom 263 received ICT, the vast majority with deferasirox (44)] provided prospective evidence that ICT has a positive effect. In addition to OS, in this cohort, LFS was also better amongst patients receiving ICT, with a median time to progression of 40.6 vs 27.3 months.

Similar results were achieved in an observational study on 97 patients with low-/intermediate-risk MDS, with a trend towards shorter LFS in patients who did not receive ICT: at 30 months,

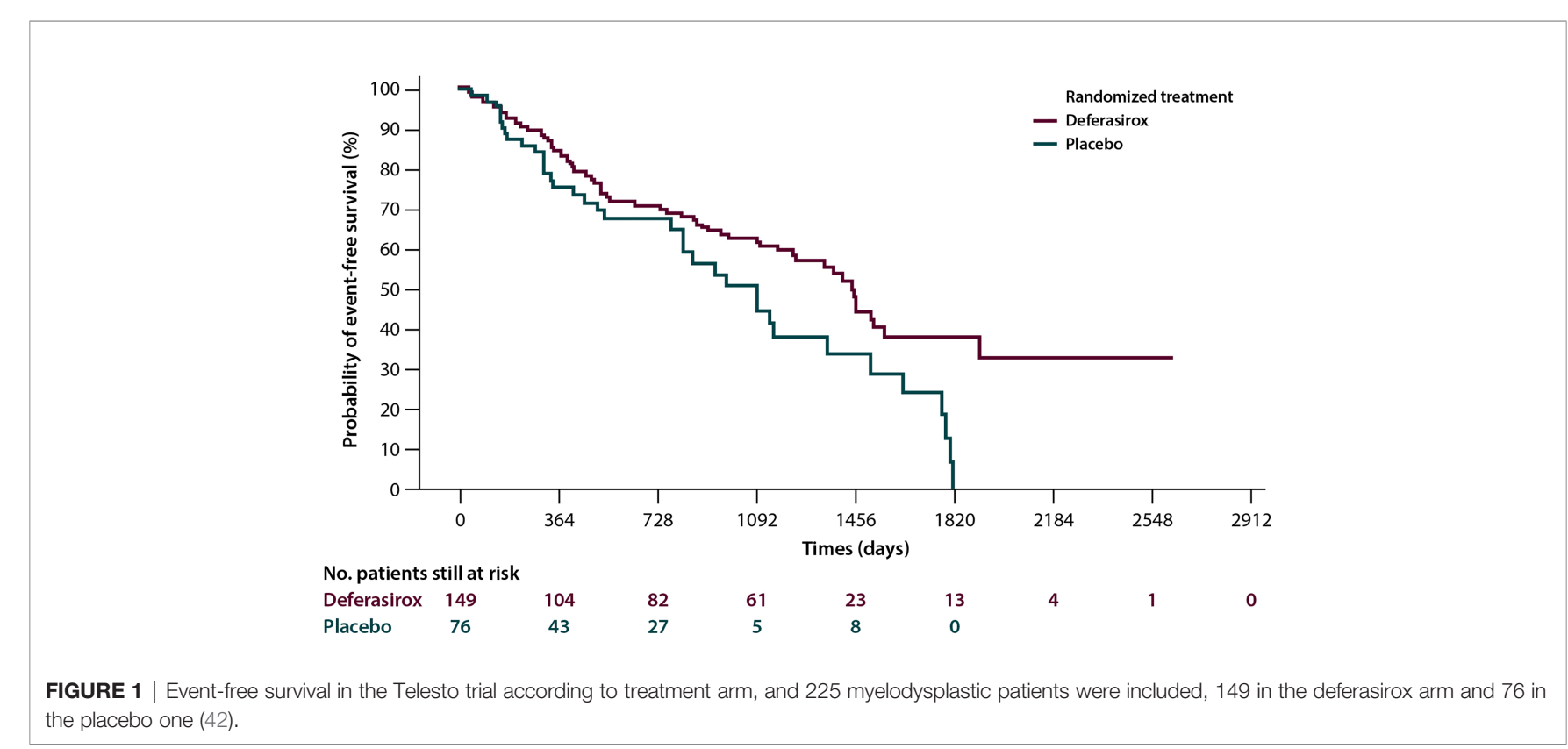


$34 \%$ of patients not treated with an iron chelator had progressed to AML vs $17 \%$ of patients receiving iron chelators (45).

- Hematological improvement. In several clinical studies, including the EPIC (Evaluation of Patients' Iron Chelation with Exjade) study, a percentage of patients (10-20\%) treated with deferasirox obtained a positive effect on hematopoiesis, with erythroid hematological recovery (30-33), as reported in Table 1. Similar results were also observed in Italian and international real-world studies. In the data reported by two Italian regional registries, the Roman Myelodysplasia Group (GROM) and the Basilicata Registry, including a total of 118 patients with transfusion-dependent MDS treated with deferasirox, hematologic improvements in the erythroid, platelet, and neutrophil series were reported in 17.6, 5.9, and $7.1 \%$ of cases, respectively (35). In the prospective randomized TELESTO study, 27/127 patients (22.3\%) receiving deferasirox obtained hematological improvement; however, it is worth of note that a similar rate of hematological improvement (14/68 patients, $20.6 \%$ ) was also observed in the placebo arm of the study (42). Although several mechanisms have been postulated, the reduced production of iron-dependent ROS and inhibition of NFk-B activity would appear to be particularly relevant factors (Figure 2).

\section{Higher-Risk MDS Patients: How and When to Chelate}

According to prognostic scores such as the IPSS, R-IPSS, and WHO Prognostic Scoring System (WPSS), patients with "highrisk" MDS account for $20-30 \%$ of the total population. Historically, life expectancy in this group of patients has been reported between 1 and 2 years; however, the introduction of disease-modifying therapies (such as hypomethylating agents) has led to longer survival and better prognosis (16).

The main causes of death in two-thirds of patients with highrisk MDS are strongly correlated with cardiac events and infectious complications (greater risk in transfused patients than in those who do not receive transfusions), at least partly due to the impact of iron-induced toxicity (46).

The main limiting factors to start ICT are the short OS of these patients, the potential higher risk of renal or hepatic impairment and gastrointestinal bleeding.

The data currently available are constituted by a retrospective study on 51 patients with transfusion-dependent intermediate-/ high-risk MDS (in $71 \%$ azacitidine was co-administered). Treatment with deferasirox in these patients showed a significant clinical benefit in terms of decrease in ferritin levels, liver marker normalization, and (in one case) hematological improvement, without significant additional toxicity (median follow-up was 35.3 months, and median OS 37.5 months) (3). Some registries (US Medicare, SEER) that already reported a higher incidence of infections in transfused than in nontransfused MDS patients (45-47) reported data on deferasirox treatment able to reduce risk of infection in patients more likely suffering these events for iron toxicity exposure due to transfusion. Prospective studies evaluating the combination of azazitidine and deferasirox in HR-MDS are ongoing.

In patients with high-risk MDS, there is also new evidence of a significant effect in terms of genotoxicity accumulation of IOLinduced mutations, which might add a biological strong rationale for the administration of ICT. In vivo evidence also shows that oxidative stress may contribute to the hypermethylation of important tumor suppressor genes, suggesting a synergic action of ICT and treatment with hypomethylating agents (48).

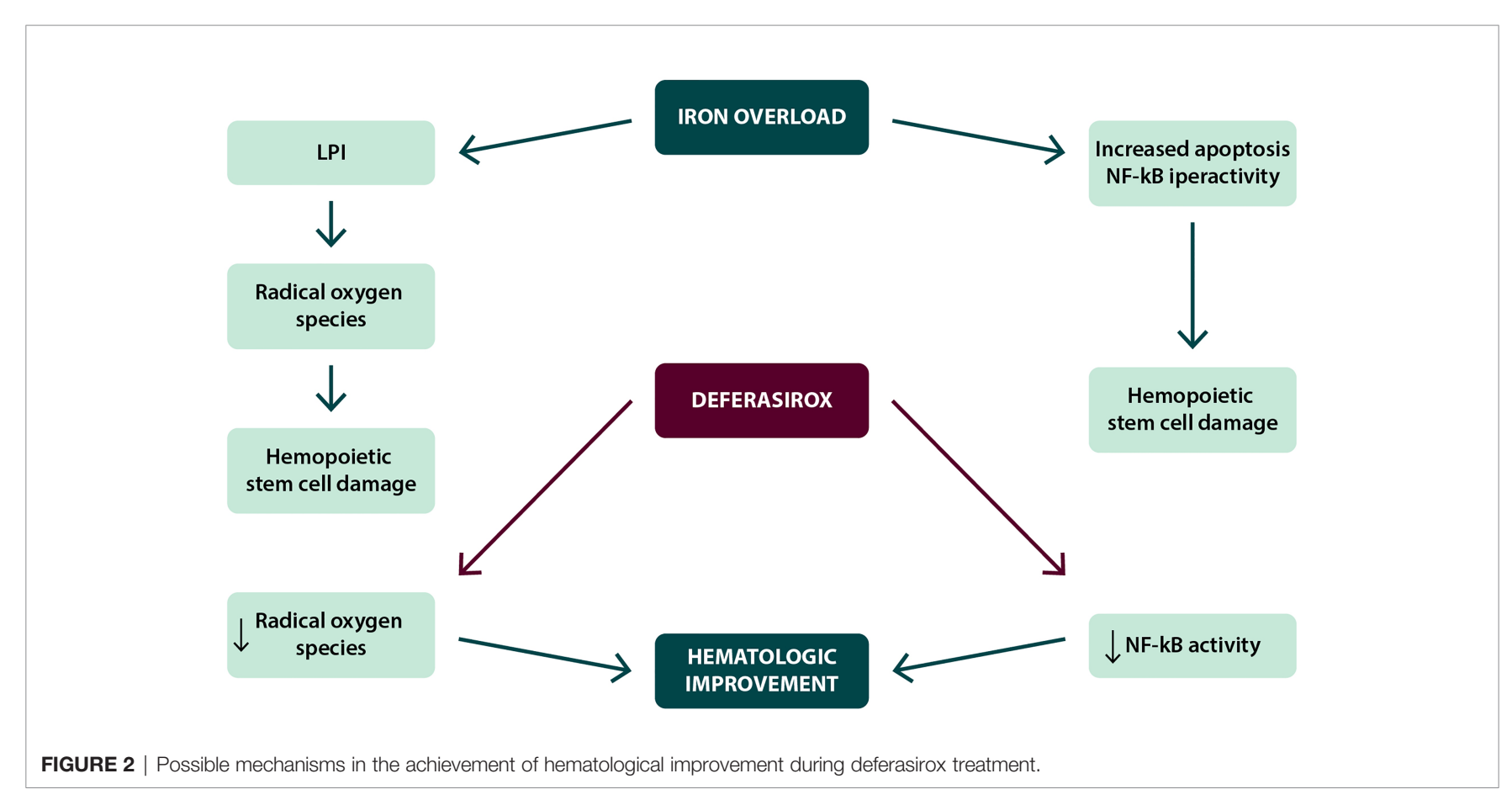


The ideal candidates for ICT amongst patients with higherrisk MDS are those with a longer life expectancy and more favorable prognostic factors, including

- good general health and age $\leq 65$ years,

- absence of significant comorbidities, and

- patients who are candidates for allogeneic transplantation and/or treatment with demethylating agents.

\section{When to Start Iron Chelation Therapy and When to Discontinue Iron Chelation Therapy}

The possible parameters for starting ICT in patients with highrisk MDS are the same as described previously for lower-risk patients. Decisions regarding the duration of the treatment should also be based on the same criteria already described.

\section{Efficacy and Safety of Deferasirox in Patients With MDS: How to Administer Iron Chelation Therapy \\ How to Measure the Efficacy of Iron Chelation Therapy in Terms of the Reduction in Iron Overload in Patients With MDS}

The assessment of the efficacy of the treatment may be based on two types of parameters:

1. Iron toxicity markers

2. Patient clinical outcome

The biochemical and tissue damage markers that indicate a reduction in IOL and constitute the parameters for the administration of deferasirox are

- transferrin saturation,

- serum ferritin,

- aminotransferases (a decrease in aminotransferase with improvement of liver function has been observed in a significant proportion of patients with abnormal values at baseline),

- measurement of labile plasma iron (LPI), where available, and

- T2-weighted MRI (where available).

In the published clinical studies, serum ferritin levels serially measured throughout the observation period were the main used parameters $(16,49)$.

Clinical outcomes that can be directly measured and therefore compared, alongside cardiac events, infectious complications, and disease progression, were hematologic response rates, in terms of trilinear improvement (erythroid, platelet, and neutrophil compartment). The relationship between these parameters and the reduction in the markers of IOL was significant in some cases, but not in all (46).

Any kind of hematologic responses, which was observed in $20 \%$ of patients treated with deferasirox, can be considered an additional clinical benefit constituting a further reason for continuing ICT, and its absence does not constitute an indication for discontinuing treatment and it does not, therefore, represent a criterion for a therapeutic decision-making.

\section{How to Monitor the Safety of the Iron Chelation}

\section{Therapy}

The most important studies in MDS setting reported data on old formulation deferasirox safety profile, and the most common side effects were gastrointestinal (GI) ones due to lactose; in particular, diarrhea, nausea, and abdominal pain could occur. The safety profile of deferasirox's new formulation, now available in filmcoated tablets, was studied in ECLIPSE trial: the incidence and type of adverse events (AEs) for the new formulation are similar to the previous one (tablets for oral suspension), whereas the incidence of severe AEs (SAE) is lower (19.5 versus 25.6\%), especially for GI events such as diarrhea, nausea, and vomiting (50). The study also reports the same similarity also for hepatic and renal safety (the $\mathrm{CrCl}$ values to start treatment remained $\geq 60 \mathrm{ml} / \mathrm{min}$ ). Patients receiving treatment with deferasirox can be subjected to the same safety monitoring scheme.

\section{Guidance to be Given to Patients on Iron Chelation Therapy}

It is essential to provide patients with clear and complete information concerning the main aspects of ICT. These aspects regard

- treatment compliance, which is extremely important for the efficacy of therapy, as the better treatment compliance observed amongst patients treated with the new formulation (92.9 vs. $85.3 \%)$ coincided with a greater decrease in ferritin levels in this group (median: $-14 \%$ vs. $-4.1 \%$ ) (50); and

- safety management: it is important to instruct patients how to manage adverse events and eventually refer them promptly to their physician.

Hence, patient education can improve compliance with ICT and reduce the complications associated with IOL (51).

\section{IRON CHELATION THERAPY IN MYELOFIBROSIS AND OTHER CHRONIC ANEMIAS}

\section{Pathogenesis and Clinical Significance of Anemia in Myelofibrosis}

The Pathogenetic Mechanisms of Anemia in Myelofibrosis

Myelofibrosis (MF) is a rare hematological condition classified in the group of chronic BCR-ABL1- negative myeloproliferative neoplasms (MPN) (52), characterized by bone marrow fibrosis and consequent ineffective hematopoiesis, with the onset of extramedullary hematopoiesis. The signs and symptoms characterizing this condition include

- constitutional symptoms (itching, fever, night sweats and weight loss);

- symptoms associated with splenomegaly;

- symptoms due to anemia (asthenia, dyspnea, palpitations) (53): huge symptom burden, poorer quality of life, and iron 
overload associated with transfusion therapy. As bone marrow fibrosis, anemia increases progressively over time from $38 \%$ of cases with $\mathrm{Hb}<10 \mathrm{~g} / \mathrm{dl}$ at diagnosis to $64 \% 1$ year after diagnosis (54).

Although anemia is caused by bone marrow erythropoietic tissue fibrotic replacement and by ineffective production and maturation of red blood cells generated by a compensatory extramedullary erythropoiesis, these are not the only etiological factors. Other significant pathogenetic mechanisms causing anemia are splenic sequestration and hemodilution, resulting from the increase in plasma volume and abnormal production of bone marrow cytokines. As a consequence, MF is characterized by a considerable local and systemic inflammatory state, with a wide increase of inflammatory bone marrow cytokines, which in turn affect erythropoiesis in the residual functional areas of hematopoietic bone marrow. This pro-inflammatory state includes an increase in circulating hepcidin levels interfering with iron metabolism as observed in other secondary anemias (55).

MF patients present specific genetic changes too likely anemia-related: patients with Calreticulin (CALR) or MPL thrombopoietin receptor (MPL) gene mutations would appear to have a lower likelihood of developing anemia than triplenegative patients (CALR, MPL, and JAK2 wild types), with underlying unknown mechanisms at this time.

The presence of anemia is a negative variable recognized in all the scores that stratify MF patient risk from a prognostic standpoint (56), with a negative impact on life expectancy (by stratifying patients with primary MF according to the degree of anemia, we observe median OS values that range from 7.9 years in patients without anemia to 2.1 years in cases with severe anemia) (57).

Anemia and thrombocytopenia in patients with MF could worsen with treatment with ruxolitinib, the first Janus Kinase 1/2 (JAK) inhibitor approved on the basis of the COMFORT and JUMP study results $(58,59)$. Ruxolitinib acts directly on the hyperactivation of the JAK-STAT pathway that underlies the disease, by selectively inhibiting the JAK-1 and JAK-2 kinases and suppressing residual bone marrow function (55). The anemia due to ruxolitinib treatment has not to be considered as negative prognostic factor, as it is often transient and does not worsen the patient's overall outcome, unlike pre-existing anemia. Most cases of anemia during ruxolitinib therapy appear within the first 6 months and are Grade 1/2, rarely requiring the discontinuation of therapy. In general, it is advisable to strictly monitor patients during the first weeks of therapy when the $\mathrm{Hb}$ levels could decrease rapidly to promptly evaluate the possible transfusion need, before increasing again in the following months, and stabilize on average approximately $10 \%$ below the baseline value (60).

The onset of anemia does not reduce the efficacy of ruxolitinib on splenomegaly and symptoms $(58,61)$, and consequently treatment is strongly recommended in anemic patients too. Similarly, it is not advisable to reduce the dose of ruxolitinib in patients who develop anemia, as this side effect seems not dosedependent: the treatment should be continued at the doses required to control the disease and established on the basis of the platelet count.

Therefore, three types of patients can be identified:

- Patients who are not transfusion-dependent at baseline

- Patients who are already transfusion-dependent at baseline and who usually remain so throughout treatment

- Patients just above the dependency threshold at baseline, who become transfusion-dependent after therapy (these borderline patients can be the most difficult to manage, as they are not used to receiving transfusion support)

\section{Iron Toxicity and Transfusion Need in Myelofibrosis}

\section{The Pathogenic Mechanisms of Oxidative Stress Iron-Mediated in Myelofibrosis and Organ Toxicity}

The main treatment for anemia consists of RBC transfusions: approximately a quarter of patients with MF are transfusiondependent at diagnosis (when dependency is defined as the administration of $>6$ units of RBC over a period of 12 weeks for $\mathrm{Hb}$ levels $<8.5 \mathrm{~g} / \mathrm{dl}$ ), and many more become so during the course of their illness (55).

In patients with $\mathrm{MF}$, characterized by a significant proinflammatory state, hepcidin levels are usually higher, with a consequent unbalance of iron metabolism and showing a negative prognostic value (62).

Although the vascular effects of free iron species have been less extensively studied, it has been observed that high circulating iron levels can worsen the atherosclerotic phenotype, especially in elderly patients: the macrophages on the vessel wall accumulate the iron produced by the increased destruction of red blood cells and abnormal iron homeostasis, with an increase in the production of ROS and decreased cholesterol outflow. The resulting oxidative stress promotes the formation of foamy cells, inflammation, apoptosis, and the deterioration of the atherosclerotic plaque. Furthermore, the high hepcidin levels typical of MF contribute to this process by blocking ferroportin and, therefore, the exportation of iron from plaque (63).

ICT can have a beneficial effect on iron-mediated endothelial dysfunction, because the binding of the labile cell iron in the vessel wall may reduce the formation of ROS and the inactivation of nitric oxide, another consequence of iron-induced toxicity. It was observed that deferasirox can significantly improve the dilation of the brachial artery and reduce carotid artery stiffness in patients with beta-thalassemia (64).

In bone marrow, IOL and the consequent oxidative stress cause an increase of genetic instability of the hematopoietic cells and the production of pro-inflammatory cytokines by bone marrow stromal cells that, in turn, may play a role on bone marrow failure in patients with MF, as it was reported in MDS (15). However, iron-induced toxicity and its negative impact on the hematopoietic microenvironment (65) might have an impact on the dysregulation of the JAK-STAT pathway itself, which is able to induce an increase in pro-inflammatory and fibrogenic cytokines and increased ROS production. In addition, patients with MF present significant NF-kB pathway activation, which 
induces the production of inflammatory cytokines (IL6, TNF $\alpha$ ) and interacts with the dysregulation of the JAK-STAT pathway to amplify the oxidative damage $(66,67)$.

\section{Assessment and Monitoring of Iron-Induced Toxicity in Patients With Myelofibrosis}

As for other conditions ferritin remains the main parameter for the evaluation of IOL although relatively less reliable in MF, due to inflammatory state. In these patients, therefore, a more significant role is played by transferrin saturation (marker of free iron release, which causes organ damage), and it should be tested together with ferritin level trends at the onset of the disease.

The role of imaging techniques (T2-weighted MRI) in patients with MF is more controversial, due both to the difficulties in distinguishing between fibrosis-induced organ damage and iron-induced toxicity and because toxic ironinduced damage and exposure to ROS may clinically occur even before iron accumulation will be evident in the hepatocytes and myocardial cells.

\section{Iron Chelation Therapy and Myelofibrosis: Iron Chelation Response Impact of Deferasirox Treatment in Reducing Ferritin and Inducing Erythroid Response in Transfusion- Dependent Myelofibrosis}

Although the observation of potentially harmful iron-induced toxicity has suggested the utility of ICT in MF in the management of anemia, the clinical evidence regarding the use of iron-chelating agents is still limited. In fact, only single case reports regarding the use of ICT in MF were available until few years ago. Recently the results of two Italian multicenter studies became available with the following results (Table 2):

- 45 patients with primary MF or Post Polycythemia Vera MF (PPV-MF)/Post Essential Thrombocythemia MF (PET-MF) treated between 2010 and 2018 in the Lombardy Hematological Network (IRON-M Study) (68)
- 48 patients with primary MF or PPV-MF/PET-MF treated by the Lazio Group (69)

These two studies report the impact of treatment with deferasirox in terms of induction of iron chelation response (ICR) and erythroid response. Based on these data, an ICR was obtained with deferasirox in approximately $30-40 \%$ of patients with $\mathrm{MF}$, whereas complete or partial hematological response (usually not accompanied by an increase in platelets and neutrophils) was observed in $20-40 \%$ of cases.

The results show that in both studies, patients who obtained an ICR experienced a progressive reduction in ferritin levels at 6 , 12 , and 18 months, compared to non-responders (68). As regards the identification of factors predictive of an ICR to deferasirox, in the study by Elli et al. (68), patients who obtained efficacious ICR presented statistically lower ferritin levels at baseline than nonresponders. Similarly, the median number of prior transfusions and the duration of the history of transfusion dependence were statistically lower/shorter amongst responders. These data highlight that an earlier access to iron chelation therapy constitutes an advantage in terms of efficacious iron chelation. On the other hand, other than the statistically significant relationship between the achievement of ICR and the obtainment of hematological improvement, it was not possible to identify factors predictive of hematological response (68).

The achievement of ICR, defined both by reduction in ferritin levels and by prolonged OS, are closely related in patients with MF treated with deferasirox (69): 2-years OS after the start of treatment was $100 \%$ in patients who responded to the ICT, compared to $70 \%$ in patients who did not experience a reduction in ferritin levels (68) (95\% CI: 46.5-84.8\%, $\mathrm{p}=0.007$ ). In patients who presented a reduction in ferritin levels, median survival from the start of therapy with deferasirox was 61.0 months (95\% CI: 18.4-103.6) compared to 15.8 months (95\% CI: 5.9-25.6) in patients who did not respond to the ICT $(p=0.001)(69)$. Therefore, by reducing the IOL, treatment with deferasirox seems to provide a significant advantage in terms of the survival in patients with MF. The rate of leukemia evolution or

TABLE 2 | Iron chelation efficacy and erythroid responses during deferasirox treatment in myelofibrosis patients.

Institution Lombardy Hematological Network (68) $\left({ }^{*}\right)$

Evaluable patients

Median duration of treatment

Iron chelating response (ICR)

$41 / 45$ pts
17.2 months (IR $3-59.5)$
Ferritin $<1,000 \mathrm{ng} / \mathrm{ml}$ or $\geq 50 \%$ decrease of baseline
ferritin: $29.3 \%$ (12 pts)
No response: $70.7 \%$ (29 pts)

No response: $70.7 \%$ (29 pts)

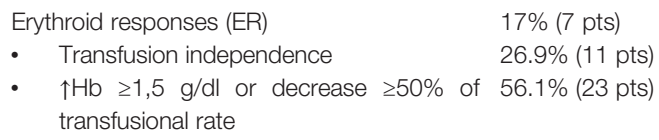

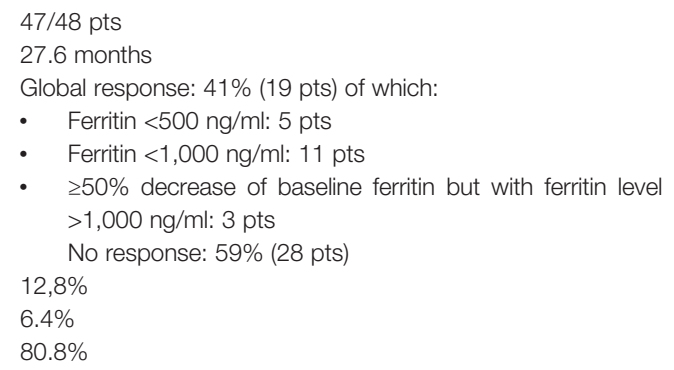

6.3 months (IR 4.3-12.1)

(*) starting dose $750 \mathrm{mg} /$ day (10 mg/kg/day); (*): Starting dose $20 \mathrm{mg} / \mathrm{kg}$ in 23 patients, $15 \mathrm{mg} / \mathrm{kg}$ in 20 patients, and $10 \mathrm{mg} / \mathrm{kg}$ in 5 patients.

IR, interquartile; pts, patients. 
progression disease seems to be lower in ICR group, with a better 2-year leukemia free survival (LFS, $\mathrm{p}=0.039$ ) (68), but this result needs to be confirmed in a larger and prospective cohort.

\section{Patients with MF in Whom There is an Indication for Initiating Iron Chelation Therapy}

The data currently available allow us to identify the eligible patient profile for ICT, for subjects with a life expectancy $>6$ months:

1. Patients with anemia not treated with ruxolitinib, when they become transfusion-dependent

2. Patients with transfusion-dependent anemia and significant symptoms and/or splenomegaly who start treatment with ruxolitinib, whose IOL is already significant at the start of therapy and will probably increase after the administration of ruxolitinib itself, as transfusion needs will increase

3. Transfusion-dependent anemic patients with an indication for HSCT, who require ICT in preparation for the transplant procedure

On the contrary, in non-anemic MF patients and who develop transfusion dependency in the early months after starting of ruxolitinib, the administration of an iron chelator may not be necessary due to the likelihood of $\mathrm{Hb}$ level recovery.

\section{When a Patient With MF Treated With Deferasirox Must Be Considered a Responder}

ICR to deferasirox is usually evaluated by taking into account ferritin value trends compared to the baseline. In the absence of standardized response criteria, ferritin levels $<1,000 \mathrm{ng} / \mathrm{ml}$ or $<500 \mathrm{ng} / \mathrm{ml}$ can be considered indicative of the achievement of ICR, as can a $\geq 50 \%$ decrease in ferritin levels compared to the baseline, regardless of the final levels.

As mentioned previously, given the inflammatory nature of the condition, although on the one hand these values are sufficient for MDS, they would appear to be less conclusive in patients with MF. Transferrin saturation rate could represent a more reliable marker of chelation efficacy useful also as markers of iron toxicity and ROS-induced damage; a threshold of $70 \%$ might be considered for this evaluation.

\section{Safety Profile of Deferasirox in Myelofibrosis}

Treatment with deferasirox in patients with MF can be associated with the onset of extra-hematological adverse events (AEs), which are primarily constituted by renal impairment: 17.7\% (70), hepatic impairment: $8.9 \%$ (68), gastrointestinal symptoms: 11.1-21.4\% (68, 69), and skin reactions: $6.7-7.2 \%(68,69)$. Overall, a definitive discontinuation of ICT secondary to toxicity of grade $\geq 2$ of DFX was reported in about a quarter of patients. Of note, no difference in term of number of AEs was seen between ICR and no ICR group; among the patients achieving ICR, no grade 3-4 toxicity was reported (68).

\section{Therapies for Myelofibrosis and Iron Chelation \\ Clinical Evidence Regarding Ruxolitinib-Deferasirox Combinations}

In recent years the advent of the specific JAK-1/JAK-2 inhibitor ruxolitinib represented the only real innovation in the treatment of MF. The use of concomitant therapy with deferasirox in MF patients treated with ruxolitinib would appear based on a clinical need and a strong biological rationale (both drugs work synergically by reducing the oxidative damage in the bone marrow and interacting with the NF-kB and JAK-STAT pathways). The limited evidence currently available (70) suggests that this combination is feasible in terms of tolerability and efficacious in reducing iron overload.

\section{Iron-Induced Toxicity, Transfusion Requirements, and Iron Chelation Therapy in Patients With Aplastic Anemia and Other Chronic Anemias}

\section{Utility of Iron Chelation in Aplastic Anemia}

Aplastic anemia (AA), a rare blood disorder, is considered the paradigm of bone marrow failure (BMF) syndromes. The disease is caused by an aberrant immune response, which causes the oligoclonal expansion of cytotoxic $\mathrm{T}$ cells, resulting in the destruction of haemopoietic stem cells (71). Clinically, it results in different grade pancytopenia (AA classified as "severe," "very severe," or "not severe" depending on bone marrow cellularity and peripheral cytopenia status).

Current treatment for AA (indicated in cases that are severe, very severe, or become transfusion-dependent) is based on allogeneic stem cell transplantation (in eligible patients) and on immunosuppressive therapy [cyclosporine, anti-thymocyte globulin (ATG)]. Patients who are not eligible due to old age or comorbidities and those who do not obtain clinical response can be managed with supportive care that includes the use of growth factors, antibiotic treatments, and transfusion therapy (54).

IOL, defined as a ferritin value $>1,000 \mathrm{ng} / \mathrm{ml}$, is present in almost $20 \%$ of patients who receive transfusions and in $6 \%$ of non-transfused patients (72). In a post-hoc analysis of the EPIC study, patients with AA were seen to have had an average of between 8 and 15 transfusion sessions in the previous year, and their median ferritin levels were 3,600-3,700 ng/ml (73). Using imaging techniques (MRI), IOL was observed in the liver in $76.4 \%$ of patients (including AA) and in the heart in $19.2 \%$ (74). The presence of an IOL in patients with severe AA reduces the efficacy of the immunosuppressive therapy and increases the risk of a relapse, confirming that it is a negative prognostic factor for the outcome of these patients (75).

Therefore, in AA there is a significant incidence of IOL, and its negative impact on clinical outcomes constitutes the rationale for using ICT in this setting. Furthermore, high ferritin levels might have a negative impact on the response to therapy and on the risk of toxicity in patients with AA undergoing a HSCT (76).

At the current time, there are no specific standardized criteria for starting ICT in patients with AA. The serum ferritin threshold value $>1,000 \mathrm{ng} / \mathrm{ml}$ can be used as a rule of thumb (75, 77-80).

The EPIC prospective study evaluated the efficacy and safety of ICT with deferasirox in 116 patients with AA (74). The analysis showed that therapy with deferasirox efficaciously reduced median serum ferritin levels: this efficacy was associated with the transfusional iron load and the dose of 
deferasirox, with higher doses of medicinal product needed to reduce the iron load in subjects with a high intake (79).

In patients with $\mathrm{AA}$, as in other blood disorders, IOL is associated with the observation of hematological response in patients that became transfusion-independent (73). In an Italian multicenter prospective study (81), hematological responses were observed with transfusion independence, associated with a significant increase in platelets, in a cohort of eight patients with AA treated with deferasirox in a real-life setting.

\section{Other Types of Anemia in Which Iron Overload Occurs Regardless of the Transfusion Load}

IOL is a common complication in patients with congenital hemolytic anemias (CHAs), a heterogeneous group of disorders that include hereditary spherocytosis, G6PD deficiency, and pyruvate-kinase (PK) deficiency. These patients can experience an IOL regardless of transfusion therapy due to the hyperhemolysis caused by the hereditary deficiency, as demonstrated by MRI evaluation that showed IOL also reported in patients with ferritin levels $<1,000 \mathrm{ng} / \mathrm{ml}$ (82). In patients with PK deficiency who do not have regular transfusions, a total prevalence of IOL (based on ferritin values) of $38 \%$ was observed, which increases (to $82 \%$ ) when MRI is used as the detection technique.

In an analysis conducted on a population of 37 cases of CHAs (26), the presence of IOL was seen to be common in patients with congenital hemolytic anemias, especially in those with PK deficiency and with congenital dyserythropoietic anemia type II (CDAII), who presented particularly high ferritin and transferrin saturation levels, even regardless of transfusion dependency. Moreover, hepatic iron overload (LIC) was observed in patients with not excessively high ferritin levels also in this study.

A specific sub-analysis of the EPIC study on a total population of 57 patients including 23 cases of hemolytic anemia (of which five cases of PK deficiency, two cases of congenital erythropoietic protoporphyria, and one patient with hereditary hemolytic anemia) showed efficacy of deferasirox in decreasing median serum ferritin levels $(-617 \mathrm{ng} / \mathrm{ml}$ at 1 year), confirming the durable response after 1 year of treatment, regardless of the underlying pathogenic mechanisms (83).

\section{MANAGEMENT OF SIDE EFFECTS AND COMORBIDITIES}

\section{Frailty of Elderly Hematological Oncology Patients and Comorbidities}

When considering a new treatment approach, it is important to consider the patient age, which is often high, and the likely presence of comorbidities; the latter must not be seen as a contraindication for ICT, rather a supplementary factor to be taken into consideration in order to support its indication. Ironmediated toxicity caused by excess free iron can even worsen an existing dysfunction or result in the emergence of concomitant subclinical conditions.

\section{Impact of Iron-Induced Toxicity on Renal Function}

Impaired renal function is closely correlated to the age of the patient; over 40 years of age, $2 / 3$ of the population present a progressive decrease in glomerular filtration rate (especially in males) (84). Changes in renal function are therefore more common in elderly patients and cardiac, hepatic or metabolic comorbidities (85).

The concomitant presence of anemia, hypoxia, and iron overload may impair the kidneys, especially in the tubular region. Moreover, these factors can cause oxidative stress in the tubular cells responsible for the resorption of water and solutes, which have a consistent ATP-dependent metabolic activity, with consequent histological and functional damage that, in turn, results in increased urinary excretion of certain solutes, including albumin, proteins, potassium, uric acid, calcium, phosphorus and bicarbonate. This excretion inevitably leads to conditions such as metabolic acidosis, bone changes, and kidney stones (85-91).

Chelation agents such as deferoxamine and deferasirox are thought to be responsible for the onset of renal changes and, in a small percentage of cases, also for severe forms of acute renal impairment, although the pathogenetic mechanism of this effect is still unclear. The onset of Fanconi syndrome (generalized proximal convoluted tubule defect) has also been observed, associated, not necessarily concomitantly, with polyuria, proteinuria, hypouricemia, hypopotassemia, hypercalciuria, hypophosphatemia, metabolic acidosis (caused by decreased bicarbonate resorption), and bone demineralization (due to the buffer effect of bone that binds with the acids) $(92,93)$.

As demonstrated by pivotal clinical studies on the use of deferasirox (94-96), up to one-third of cases present renal function changes, most of which are mild and within range of normality. These changes should not be considered clinically significant, as they are slight, non-progressive fluctuations in creatinine levels, with a less than $33 \%$ increase compared to the baseline, reversible (in most cases), and transient. In the GIMEMA MDS0306 study (31) just one in 15 cases of renal function changes was grade 3 . In most cases, the change in renal function resolves spontaneously.

IOL leads to kidney injury secondary to oxidative stress. However, iron constitutes an important co-factor in prostaglandin synthesis and in the production of ATP in the kidney tubule cells by the mitochondria (85). This results in decreased sodium and chlorine resorption localized in the proximal convoluted tubules, which in turn causes increased resorption of both electrolytes in the distal portion of the tubules (macula densa) anatomically adjacent to the glomerulus. This process transmits a vasoconstriction signal to the afferent arteriole of the glomerulus, triggering a reduction in glomerular filtration (tubuloglomerular feedback).

The decreased levels of prostaglandins, caused by the lack of production, induce vasoconstriction on the afferent arteriole that leads to the impairment of glomerular blood flow. This results in a reduction in glomerular filtration rate that, together with renal flow, normalizes when treatment is discontinued, even after 2 years of treatment $(97,98)$. When the benefits of the treatment are 
considered to outweigh the risks associated with the increase in creatinine (which is non-progressive and lower than 33\% compared to the baseline) and/or proteinuria (values lower than $0.5 \mathrm{~g} / 24 \mathrm{~h}$ ), it is possible to continue treatment with deferasirox without dose adjustments.

All patients should then undergo (also with the aid of a nephrology specialist) renal function laboratory monitoring, including assessments of glomerular and tubular function.

When changes in renal function in patients with chronic anemia eligible for ICT are observed, it is necessary to consider all factors potentially responsible for renal injury as

- anemia;

- IOL;

- viral infections (HBV, HCV, HIV);

- comorbidities (heart and liver disease, diabetes mellitus, arterial hypertension, dyslipidemia);

- smoking habits; and

- patients, especially elderly ones, who are co-administered nephrotoxic drugs (non-steroidal analgesics, antibiotics, proton pump inhibitors, and allopurinol) $(99,100)$.

\section{How to Monitor Renal Function at the Start of and During Therapy With Deferasirox}

In patients with IOL (regardless of treatment with deferasirox), it is important to monitor renal function by taking into consideration factors such as:

- albumin-to-creatinine ratio,

- protein-to-creatinine ratio.

Both tests are simple to perform on the first morning urine sample of the day, and the results correlate with those over $24 \mathrm{~h}$.

Other important, but less extensively studied, aspects are

- tubular function and

- venous blood gas analysis (to identify states of metabolic acidosis).

Table 3 provides a possible monitoring schedule during treatment with deferasirox.

\section{Hepatic Comorbidities and Iron Chelation}

The presence of hepatic comorbidities needs to be carefully considered for appropriate multidisciplinary management: the free iron can lead to functional changes in liver parenchyma that, if not appropriately managed, can result in cirrhosis and liver cancer.

Treatment with deferasirox is not recommended in patients with severe hepatic impairment (Child-Pugh class C), whereas for ChildPugh class B patients, who present moderate hepatic impairment, the dose should be considerably decreased and progressively increased if needed. However, baseline hypertransaminase should not be considered an absolute contraindication to start therapy, as it may be sign of iron-induced toxicity that will be reduced by ICT $(101,102)$. For a correct management of hepatic enzymes, it is important to perform baseline tests and constant monitoring of AST/ALT, bilirubin and alkaline phosphatase, and of the transfusion burden (main cause of transaminase elevation, which conditions the adjustment of the dose of iron chelator). In order to identify the cause of the liver disease, it is therefore essential to work closely with a hepatology specialist.

\section{The Role of T2-Weighted MRI in Establishing the Relationship Between Liver Disease and Iron Overload}

$\mathrm{MRI}$ and the transverse relaxation rate $\left(\mathrm{R} 2^{*}\right)$ are non-invasive methods for a quantitative assessment of the iron content of almost the whole organ, unlike biopsy. While these methods are well established in thalassemic patients, the use of MRI in transfusion-dependent patients is increasing in recent years $(103,104)$. This can be limited by the fact that most of transfusion-dependent patients are elderly ones, in whom the organ damage may occur even before iron accumulates in liver and heart cells; this may correlate with higher mortality in this group of patients (105). A recently published Italian cooperative study (MIOMED) well demonstrated the fundamental role of T2*-MRI in detecting IOL: amongst 50 patients affected by low-/ intermediate-1 MDS, 13 showed a hepatic and 13 a cardiac IOL. The hepatic involvement was significantly conditioned by transfusion load that, at the contrary, did not influence the cardiac status. When patients were prospectively evaluated,

TABLE 3 | Optimum renal monitoring schedule.

\begin{tabular}{|c|c|c|c|c|}
\hline Tests & Baseline & First months & First 6 months & Every 6 months \\
\hline $\begin{array}{l}\text { Nephrology consultation } \\
\text { General functional markers: }\end{array}$ & $x$ & & & \\
\hline - Creatinine & $x$ & $X$ & $x$ & $x$ \\
\hline - Urinalysis & $x$ & X (every week for first month) & $x$ & $x$ \\
\hline - Cystatin C & $x$ & & & $x$ \\
\hline - Urinary protein/creatinine ratio (mg/g) & $x$ & & $X$ (every month for 6 months) & $x$ \\
\hline Markers of glomerular function: & $x$ & & $X$ (every month for 6 months) & $x$ \\
\hline $\begin{array}{l}\text { - Urinary albumin/creatinine ratio }(\mathrm{mg} / \mathrm{g}) \\
\text { Markers of tubular function: }\end{array}$ & & & & $x$ \\
\hline - Urinary Beta2-microglobulin/creatinine ratio $(\mathrm{mcg} / \mathrm{g})$ & $x$ & & & $x$ \\
\hline - Urinary calcium/creatinine ratio (mg/g) & $x$ & & & $x$ \\
\hline - Urinary phosphorus/creatinine ratio (mg/g) & $x$ & & & $x$ \\
\hline - Urinary NGAL/creatinine ratio (mcg/g) & $x$ & & & $x$ \\
\hline - Venous blood gas analysis & $x$ & & & $x$ \\
\hline
\end{tabular}


after 12 months two (non-chelated) developed hepatic IO and other two heart damage (106).

\section{Patients on Polytherapy: The Most Common Pharmacological Interactions With Deferasirox \\ The Clinical Role of and Rationale for Plasma Deferasirox Testing}

From a pharmacokinetic standpoint, deferasirox is characterized by a somewhat reduced volume of distribution, circulation that is 99\% bound to serum proteins, especially albumin, metabolism that occurs largely by UGT1A1-mediated glucuronidation (and $8 \%$ in the liver by cytochromes), and fecal elimination (107).

It has been observed $(108,109)$ that the plasma levels of deferasirox are closely influenced by different polymorphisms, such as the levels of enzymes involved in the metabolism of the medicinal product and of efflux pumps (UTG1A1, CYP1A1, CYP1A2, CYP2D6, ABCG2), which therefore directly influence the safety and efficacy profile of the medicinal product. For example, toxicity in patients with homozygosity for UGT1A1*6 is some 14 times greater than wild-type patients.

Given the number of genes involved, typing is challenging in clinical practice; this difficulty also regards hepatic transporters like MRP2, involved in the biliary excretion of the medicinal product, whose polymorphisms can increase hepatotoxicity seven-fold (108).

One solution could be to test plasma deferasirox levels, although this approach is not currently used in clinical practice.

\section{Products That May Interact With Deferasirox}

For patients with MF and MDS, concomitant use of medicinal products is an important issue. As mentioned previously, great care is required when using medicinal products such as non-steroidal antiinflammatory drugs (NSAIDs) and angiotensin converting enzyme (ACE) inhibitors, whereas there is no literature evidence available for other interactions, such as deferasirox + erythropoietin, lenalidomide, and demethylating agents (azacitidine and decitabine).

In literature, there are comforting data regarding the synergistic use of deferasirox with other medicinal products: for example, the use of this treatment with anti-leukemia therapy would appear to improve its efficacy.

In patients with MDS on treatment with demethylating agents, which have an epigenetic effect, deferasirox has been reported to be additive or synergistic with azacitidine and decitabine (an association that reduces proliferation, increases apoptosis, and halts the cell cycle in leukemia cell lines and has a more potent effect than the individual products) (110). Moreover, treatment with deferasirox results in the upregulation of the HJV gene that encodes for hemojuvelin, suggesting that deferasirox might play a role in the demethylation of certain agents together with decitabine (110).

The other therapeutic effects of deferasirox regard the upregulation of TP53 oncosuppressor gene expression (111) and reduction in the outflow proteins, such as the P-glycoprotein, the levels of which are increased by iron through the production of ROS, which decreases after treatment with deferasirox and increases the efficacy of chemotherapy agents (112).

Synergistic use of deferasirox and eltrombopag increases the mobilization of cell iron by the latter, which acts as a shuttle that removes the iron present in the tissues and rapidly transfers it to the former $(113,114)$.

In patients undergoing HSCT, special attention must be dedicated to busulfan and specific inhibitors (ibrutinib, ruxolitinib), as concomitant use with deferasirox can increase the plasma levels of these agents.

\section{CONCLUSIONS}

In patients with MF and MDS, but also with $\mathrm{AA}$ and hemolytic anemias, the prognosis is not merely associated with individual factors such as age, comorbidities, or underlying condition, but also with complications associated with the degree of cytopenia present (severity of anemia, hemorrhages, and infections) and the treatment that they receive (blood transfusions, allogeneic transplants, etc.). In these patients, any therapeutic interventions should also face not only the management of comorbidities but also complications caused by the evolution of disease and adverse effects of primary treatments.

The excess iron, associated with direct and indirect toxicity on the various tissues, leads to a worsening in age-related comorbidities, ultimately resulting in cumulative organ damage. Iron-induced toxicity also affects the evolution of the MDS or MF, by increasing cellular genomic instability and altering the bone marrow stroma through the oxidative stress, thus favoring progression to acute leukemia $(15,65)$.

The performance of a multidisciplinary evaluation of patients treated with deferasirox, at baseline and during follow-up, makes it possible to improve the therapeutic approach and optimally manage elderly patients with MF and MDS, consequently avoiding the need to discontinue specific therapy and reducing the risk of developing organ damage.

\section{AUTHOR CONTRIBUTIONS}

GP, SG, RR, and RL conceived the manuscript and prepared the first draft. All authors critically revised the article for important intellectual content. All authors gave final approval of the version to be published and agreed to be accountable for all aspects of the work in ensuring that questions related to the accuracy or integrity of any part of the work are appropriately investigated and resolved. All authors contributed to the article and approved the submitted version.

\section{FUNDING}

Medical writing assistance for the preparation of this article was funded by Novartis Pharma, Italy. The funder was not involved in the writing of this article or the decision to submit it for publication.

\section{ACKNOWLEDGMENTS}

We thank Forum Service s.r.l. for their medical editorial assistance with this manuscript. 


\section{REFERENCES}

1. Bennett JM. MDS Foundation's Working Group on Transfusional Iron Overload. Consensus Statement on Iron Overload in Myelodysplastic Syndromes. Am J Hematol (2008) 83(11):858-61. doi: 10.1002/ajh.21269

2. Santini V, Alessandrino PE, Angelucci E, Barosi G, Billio A, Di Maio M, et al. Clinical Management of Myelodysplastic Syndromes: Update of SIE, SIES, GITMO Practice Guidelines. Leuk Res (2010) 34(12):1576-88. doi: 10.1016/j.leukres.2010.01.018

3. Musto P, Maurillo L, Simeon V, Poloni A, Finelli C, Balleari, et al. IronChelating Therapy With Deferasirox in Transfusion-Dependent, Higher Risk Myelodysplastic Syndromes: A Retrospective, Multicenter Study. Br J Hematol (2017) 177(5):741-50. doi: 10.1111/bjh.14621

4. Leitch HA. Controversies Surrounding Iron Chelation Therapy for MDS. Blood Rev (2011) 25(1):17-31. doi: 10.1016/j.blre.2010.09.003

5. Vinchi F, Hell S, Platzbecker U. Controversies on the Consequences of Iron Overload and Chelation in MDS. Hemasphere (2020) 4(3):e357. doi: $10.1097 /$ HS9.0000000000000357

6. Gattermann N. Do Recent Randomized Trial Results Influence Which Patients With Myelodysplastic Syndromes Receive Iron Chelation? Hematol Oncol Clin North Am (2020) 34(2):465-73. doi: 10.1016/ j.hoc.2019.10.006

7. Liu H, Yang N, Meng S, Zhang Y, Zhang H, Zhang W. Iron Chelation Therapy for Myelodysplastic Syndrome: A Systematic Review and MetaAnalysis. Clin Exp Med (2020) 20(1):1-9. doi: 10.1007/s10238-019-00592-5

8. Zeidan AM, Giri S, DeVeaux M, Ballas SK, Duong VH. Systematic Review and Meta-Analysis of the Effect of Iron Chelation Therapy on Overall Survival and Disease Progression in Patients With Lower-Risk Myelodysplastic Syndromes. Ann Hematol (2019) 98(2):339-50. doi: 10.1007/s00277-018-3539-7

9. Angelucci E, Cianciulli P, Finelli C, Mecucci C, Voso MT, Tura S. Unraveling the Mechanisms Behind Iron Overload and Ineffective Hematopoiesis in Myelodysplastic Syndromes. Leuk Res (2017) 62:108-15. doi: 10.1016/j.leukres.2017.10.001

10. Pilo F, Angelucci E. A Storm in the Niche: Iron, Oxidative Stress and Haemopoiesis. Blood Rev (2018) 32:29-35. doi: 10.1016/j.blre.2017.08.005

11. Santini V, Girelli D, Sanna A, Martinelli N, Duca L, Campostrini, et al. Hepcidin Levels and Their Determinants in Different Types of Myelodysplastic Syndromes. PloS One (2011) 6:e23109. doi: 10.1371/ journal.pone.0023109

12. Camaschella C, Nai A. Ineffective Erythropoiesis and Regulation of Iron Status in Iron Loading Anemias. Br J Hematol (2016) 172:512-23. doi: 10.1111/bjh.13820

13. Shenoy N, Vallumsetla N, Rachmilewitz E, Verma A, Ginzburg Y. Impact of Iron Overload and Potential Benefit From Iron Chelation in Low-Risk Myelodysplastic Syndrome. Blood (2014) 124(6):873-81. doi: 10.1182/ blood-2014-03-563221

14. Weber S, Parmon A, Kurrle N, Schnütgen F, Serve H. The Clinical Significance of Iron Overload and Iron Metabolism in Myelodysplastic Syndrome and Acute Myeloid Leukemia. Front Immunol (2021) 11:627662. doi: 10.3389/fimmu.2020.627662

15. Gattermann N. Iron Overload in Myelodysplastic Syndromes (MDS). Int J Hematol (2018) 107(1):55-63. doi: 10.1007/s12185-017-2367-1

16. Zeidan AM, Griffiths EA. To Chelate or Not to Chelate in MDS: That Is the Question! Blood Rev (2018) 32(5):368-77. doi: 10.1016/j.blre.2018.03.002

17. Platzbecker U, Kubasch AS, Homer-Bouthiette C, Prebet T. Current Challenges and Unmet Medical Needs in Myelodysplastic Syndromes. Leukemia (2021) 35(8):2182-98. doi: 10.1038/s41375-021-01265-7

18. Germing U, Oliva EN, Hiwase D, Almeida A. Treatment of Anemia in Transfusion-Dependent and Non-Transfusion-Dependent Lower-Risk MDS: Current and Emerging Strategies. Hemasphere (2019) 3(6):e314. doi: 10.1097/HS9.0000000000000314

19. Jin S, Su H, Tran NT, Song J, Lu SS, Li Y, et al. Splicing Factor SF3B1K700E Mutant Dysregulates Erythroid Differentiation via Aberrant Alternative Splicing of Transcription Factor TAL1. PloS One (2017) 12:e0175523. doi: 10.1371/journal.pone.0175523

20. Malcovati L, Stevenson K, Papaemmanuil E, Neuberg D, Bejar R, Boultwood J, et al. SF3B1-Mutant MDS as a Distinct Disease Subtype: A Proposal From the International Working Group for the Prognosis of MDS. Blood (2020) 136(2):157-70. doi: 10.1182/blood.2021012067

21. Visconte V, Avishai N, Mahfouz R, Tabarroki A, Cowen J, SharghiMoshtaghin R, et al. Distinct Iron Architecture in SF3B1-Mutant Myelodysplastic Syndrome Patients Is Linked to an SLC25A37 Splice Variant With a Retained Intron. Leukemia (2015) 29(1):188-95. doi: 10.1038/leu.2014.170

22. Schneider RK, Schenone M, Ferreira MV, Kramann R, Joyce CE, Hartigan C, et al. Rps14 Haploinsufficiency Causes a Block in Erythroid Differentiation Mediated by S100A8 and S100A9. Nat Med (2016) 22(3):288-97. doi: $10.1038 / \mathrm{nm} .4047$

23. Inokura K, Fujiwara T, Saito K, Iino T, Hatta S, Okitsu Y, et al. Impact of TET2 Deficiency on Iron Metabolism in Erythroblasts. Exp Hematol (2017) 49:56-67.e5. doi: 10.1016/j.exphem.2017.01.002

24. Angelucci E, Pilo F. Iron Chelation Therapy in MDS - The Final Answer. Clin Lymphoma Myeloma (2019) 19(S1):S75-6. doi: 10.1016/j.clml. 2019.07.425

25. de Swart L, Hendriks JC, van der Vorm LN, Cabantchik ZI, Evans PJ, Hod EA, et al. Second International Round Robin for the Quantification of Serum Non-Transferrin-Bound Iron and Labile Plasma Iron in Patients With IronOverload Disorders. Haematologica (2016) 101(1):38-45. doi: 10.3324/ haematol.2015.133983

26. Barcellini W, Zaninoni A, Gregorini AI, Soverini G, Duca L, Fattizzo B, et al. Iron Overload in Congenital Haemolytic Anemias: Role of Hepcidin and Cytokines and Predictive Value of Ferritin and Transferrin Saturation. $\mathrm{Br} \mathrm{J}$ Hematol (2019) 185(3):523-31. doi: 10.1111/bjh.15811

27. Brissot $\mathrm{P}$, Ropert M, Le Lan C, Loréal O. Non-Transferrin Bound Iron: A Key Role in Iron Overload and Iron Toxicity. Biochim Biophys Acta (2012) 1820(3):403-10. doi: 10.1016/j.bbagen.2011.07.014

28. Greenberg PL, Stone RM, Al-Kali A, Barta SK, Bejar R, Bennett JM, et al. Myelodysplastic Syndromes, Version 2.2017, NCCN Clinical Practice Guidelines in Oncology. J Natl Compr Canc Netw (2017) 15(1):60-87. doi: 10.6004/jnccn.2017.0007

29. Malcovati L, Hellström-Lindberg E, Bowen D, Adès L, Cermak J, Del Cañizo C, et al. Diagnosis and Treatment of Primary Myelodysplastic Syndromes in Adults: Recommendations From the European LeukemiaNet. Blood (2013) 122(17):2943-64. doi: 10.1182/blood-2013-03-492884

30. Gattermann N, Finelli C, Porta MD, Fenaux P, Ganser A, Guerci-Bresler A, et al. Deferasirox in Iron-Overloaded Patients With Transfusion-Dependent Myelodysplastic Syndromes: Results From the Large 1-Year EPIC Study. Leuk Res (2010) 34(9):1143-50. doi: 10.1016/j.leukres.2010.03.009

31. Angelucci E, Santini V, Di Tucci AA, Quaresmini G, Finelli C, Volpe A, et al. Deferasirox for Transfusion-Dependent Patients With Myelodysplastic Syndromes: Safety, Efficacy, and Beyond (GIMEMA MDS0306 Trial). Eur J Hematol (2014) 92(6):527-36. doi: 10.1111/ejh.12300

32. Nolte F, Höchsmann B, Giagounidis A, Lübbert M, Platzbecker U, Haase D, et al. Results From a 1-Year, Open-Label, Single Arm, Multi-Center Trial Evaluating the Efficacy and Safety of Oral Deferasirox in Patients Diagnosed With Low and Int-1 Risk Myelodysplastic Syndrome (MDS) and Transfusion-Dependent Iron Overload. Ann Hematol (2013) 92(2):191-8. doi: 10.1007/s00277-012-1594-z

33. List AF, Baer MR, Steensma DP, Raza A, Esposito J, Martinez-Lopez N, et al. Deferasirox Reduces Serum Ferritin and Labile Plasma Iron in RBC Transfusion-Dependent Patients With Myelodysplastic Syndrome. J Clin Oncol (2012) 30(17):2134-9. doi: 10.1200/JCO.2010.34.1222

34. Breccia M, Finsinger P, Loglisci G, Federico V, Santopietro M, Colafigli G, et al. Deferasirox Treatment for Myelodysplastic Syndromes: "Real-Life" Efficacy and Safety in a Single-Institution Patient Population. Ann Hematol (2012) 91(9):1345-9. doi: 10.1007/s00277-012-1481-7

35. Maurillo L, Breccia M, Buccisano F, Voso MT, Niscola P, Trapè G, et al. Deferasirox Chelation Therapy in Patients With Transfusion-Dependent MDS: A 'Realworld' Report From Two Regional Italian Registries: Gruppo Romano Mielodisplasie and Registro Basilicata. Eur J Hematol (2015) 95 (1):52-6. doi: 10.1111/ejh.12476

36. Improta S, Villa MR, Volpe A, Lombardi A, Stiuso P, Cantore N, et al. Transfusion-Dependent Low-Risk Myelodysplastic Patients Receiving Deferasirox: Long-Term Follow-Up. Oncol Lett (2013) 6(6):1774-8. doi: $10.3892 / 01.2013 .1617$ 
37. Gattermann N, Jarisch A, Schlag R, Blumenstengel K, Goebeler M, Groschek $M$, et al. Deferasirox Treatment of Iron-Overloaded Chelation-Naïve and Prechelated Patients With Myelodysplastic Syndromes in Medical Practice: Results From the Observational Studies Extend and Exjange. Eur J Hematol (2012) 88(3):260-8. doi: 10.1111/j.1600-0609.2011.01726.x

38. Mainous AG3rd, Tanner RJ, Hulihan MM, Amaya M, Coates TD. The Impact of Chelation Therapy on Survival in Transfusional Iron Overload: A Meta-Analysis of Myelodysplastic Syndrome. Br J Hematol (2014) 167 (5):720-3. doi: 10.1111/bjh.13053

39. Leitch HA, Parmar A, Wells RA, Chodirker L, Zhu N, Nevill TJ, et al. Overall Survival in Lower IPSS Risk MDS by Receipt of Iron Chelation Therapy, Adjusting for Patient-Related Factors and Measuring From Time of First Red Blood Cell Transfusion Dependence: An MDS-CAN Analysis. Br J Hematol (2017) 179:83-97. doi: 10.1111/bjh.14825

40. Hoeks M, Yu G, Langemeijer S, Crouch S, de Swart L, Fenaux P, et al. EUMDS Registry Participants. Impact of Treatment With Iron Chelation Therapy in Patients With Lower-Risk Myelodysplastic Syndromes Participating in the European MDS Registry. Hematologica (2020) 105 (3):640-51. doi: 10.3324/hematol.2018.212332

41. Remacha ÁF, Arrizabalaga B, Villegas A, Durán MS, Hermosín L, de Paz R, et al. Evolution of Iron Overload in Patients With Low-Risk Myelodysplastic Syndrome: Iron Chelation Therapy and Organ Complications. Ann Hematol (2015) 94(5):779-87. doi: 10.1007/s00277-014-2274-y

42. Angelucci E, Li J, Greenberg P, Wu D, Hou M, Montano Figueroa EH, et al. Chelation in Transfusion-Dependent Patients With Low- to Intermediate-1Risk Myelodysplastic Syndromes: A Randomized Trial. Ann Intern Med (2020) 172(8):513-22. doi: 10.7326/M19-0916

43. Malcovati L, Della Porta MG, Cazzola M. Predicting Survival and Leukemic Evolution in Patients With Myelodysplastic Syndrome. Hematologica (2006) 91(12):588-1590.

44. Lyons RM, Marek BJ, Paley C, Esposito J, Garbo L, DiBella N, et al. Comparison of 24-Month Outcomes in Chelated and non-Chelated Lower-Risk Patients With Myelodysplastic Syndromes in a Prospective Registry. Leuk Res (2014) 38(2):149-54. doi: 10.1016/j.leukres.2013.11.004

45. Rose C, Brechignac S, Vassilief D, Pascal L, Stamatoullas A, Guerci A, et al. Does Iron Chelation Therapy Improve Survival in Regularly Transfused Lower Risk MDS Patients? A Multicenter Study by the GFM (Groupe Francophone Des Myelodysplasies). Leuk Res (2010) 34(7):864-70. doi: 10.1016/j.leukres.2009.12.004

46. Goldberg SL, Chen E, Corral M, Guo A, Mody-Patel N, Pecora AL, et al. Incidence and Clinical Complications of Myelodysplastic Syndromes Among United States Medicare Beneficiaries. J Clin Oncol (2010) 28 (17):2847-52. doi: 10.1200/JCO.2009.25.2395

47. Fenaux P, Mufti GJ, Hellstrom-Lindberg E, Santini V, Finelli C, Giagounidis A, et al. Efficacy of Azacitidine Compared With That of Conventional Care Regimens in the Treatment of Higher-Risk Myelodysplastic Syndromes: A Randomised, Open-Label, Phase III Study. Lancet Oncol (2009) 10(3):22332. doi: 10.1016/S1470-2045(09)70003-8

48. Gonçalves AC, Cortesão E, Oliveiros B, Alves V, Espadana AI, Rito L, et al. Oxidative Stress Levels Are Correlated With P15 and P16 Gene Promoter Methylation in Myelodysplastic Syndrome Patients. Clin Exp Med (2016) 16 (3):333-43. doi: 10.1007/s10238-015-0357-2

49. Porter JB, Elalfy M, Taher A, Aydinok Y, Lee SH, Sutcharitchan P, et al. Limitations of Serum Ferritin to Predict Liver Iron Concentration Responses to Deferasirox Therapy in Patients With Transfusion-Dependent Thalassaemia. Eur J Hematol (2017) 98(3):280-8. doi: 10.1111/ejh.12830

50. Taher AT, Origa R, Perrotta S, Kourakli A, Ruffo GB, Kattamis A, et al. New Film-Coated Tablet Formulation of Deferasirox Is Well Tolerated in Patients With Thalassemia or Lower-Risk MDS: Results of the Randomized, Phase II ECLIPSE Study. Am J Hematol (2017) 92(5):420-8. doi: 10.1002/ajh.24668

51. Zeidan AM, Pullarkat VA, Komrokji RS. Overcoming Barriers to Treating Iron Overload in Patients With Lower-Risk Myelodysplastic Syndrome. Crit Rev Oncol Hematol (2017) 117:57-66. doi: 10.1016/j.critrevonc.2017.07.002

52. Palumbo GA, Stella S, Pennisi MS, Pirosa C, Fermo E, Fabris S, et al. Role of New Technologies in Myeloproliferative Neoplasms. Front Oncol (2019) 9:321. doi: 10.3389/fonc.2019.00321

53. Komrokji RS, Verstovsek S, Padron E, List AF. Advances in the Management of Myelofibrosis. Cancer Control (2012) 19(4 Suppl):4-15. doi: 10.1177/ $107327481201904 s 04$
54. Tefferi A, Lasho TL, Jimma T, Finke CM, Gangat N, Vaidya R, et al. One Thousand Patients With Primary Myelofibrosis: The Mayo Clinic Experience. Mayo Clin Proc (2012) 87(1):25-33. doi: 10.1016/ j.mayocp.2011.11.001

55. Naymagon L, Mascarenhas J. Myelofibrosis-Related AnemiaAnemia: Current and Emerging Therapeutic Strategies. HemaSphere (2017) 1(1):e1. doi: 10.1097/HS9.0000000000000001

56. Carreau N, Tremblay D, Savona M, Kremyanskaya M, Mascarenhas J. Ironing Out the Details of Iron Overload in Myelofibrosis: Lessons From Myelodysplastic Syndromes. Blood Rev (2016) 30(5):349-56. doi: 10.1016/ j.blre.2016.04.003

57. Nicolosi M, Mudireddy M, Lasho TL, Hanson CA, Ketterling RP, Gangat N, et al. Sex and Degree of Severity Influence the Prognostic Impact of Anemia in Primary Myelofibrosis: Analysis Based on 1109 Consecutive Patients. Leukemia (2018) 32(5):1254-8. doi: 10.1038/s41375-018-0028-x

58. Verstovsek S, Mesa RA, Gotlib J, Levy RS, Gupta V, DiPersio JF, et al. A Double-Blind, Placebo-Controlled Trial of Ruxolitinib for Myelofibrosis. N Engl J Med (2012) 366(9):799-807. doi: 10.1056/NEJMoa1110557

59. Al-Ali HK, Griesshammer M, Foltz L, Palumbo GA, Martino B, Palandri F, et al. Primary Analysis of JUMP, a Phase 3b, Expanded-Access Study Evaluating the Safety and Efficacy of Ruxolitinib in Patients With Myelofibrosis, Including Those With Low Platelet Counts. Br J Hematol (2020) 189(5):888-903. doi: 10.1111/bjh.16462

60. Cervantes F, Vannucchi AM, Kiladjian JJ, Al-Ali HK, Sirulnik A, Stalbovskaya V, et al. Three-Year Efficacy, Safety, and Survival Findings From COMFORT-II, a Phase 3 Study Comparing Ruxolitinib With Best Available Therapy for Myelofibrosis. Blood (2013) 122(25):4047-53. doi: 10.1182/blood-2013-02-485888

61. Palandri F, Tiribelli M, Benevolo G, Tieghi A, Cavazzini F, Breccia M, et al. Efficacy and Safety of Ruxolitinib in Intermediate-1 IPSS Risk Myelofibrosis Patients: Results From an Independent Study. Hematol Oncol (2018) 36 (1):285-90. doi: 10.1002/hon.2429

62. Pardanani A, Finke C, Abdelrahman RA, Lasho TL, Tefferi A. Associations and Prognostic Interactions Between Circulating Levels of Hepcidin, Ferritin and Inflammatory Cytokines in Primary Myelofibrosis. Am J Hematol (2013) 88(4):312-6. doi: 10.1002/ajh.23406

63. Vinchi F, Muckenthaler MU, Da Silva MC, Balla G, Balla J, Jeney V. Atherogenesis and Iron: From Epidemiology to Cellular Level. Front Pharmacol (2014) 5:94. doi: 10.3389/fphar.2014.00094

64. Cheung YF, Chan GC, HA SY. Effect of Deferasirox (ICL670) on Arterial Function in Patients With Beta-Thalassaemia Major. Br J Hematol (2008) 141(5):728-33. doi: 10.1111/j.1365-2141.2008.07092.x

65. Isidori A, Borin L, Elli E, Latagliata R, Martino B, Palumbo G, et al. Iron Toxicity - Its Effect on the Bone Marrow. Blood Rev (2018) 32(6):473-9. doi: 10.1016/j.blre.2018.04.004

66. Fisher DAC, Malkova O, Engle EK, Miner CA, Fulbright MC, Behbehani GK, et al. Mass Cytometry Analysis Reveals Hyperactive NF Kappa B Signaling in Myelofibrosis and Secondary Acute Myeloid Leukemia. Leukemia (2017) 31(9):1962-74. doi: 10.1038/leu.2016.377

67. Elli EM, Baratè C, Mendicino F, Palandri F, Palumbo GA. Mechanisms Underlying the Anti-Inflammatory and Immunosuppressive Activity of Ruxolitinib. Front Oncol (2019) 9:1186. doi: 10.3389/fonc.2019.01186

68. Elli EM, Iurlo A, Aroldi A, Caramella M, Malato S, Casartelli, et al. Deferasirox in the Management of Iron-Overload in Patients With Myelofibrosis: A Multicenter Study From the Rete Ematologica Lombarda (IRON-M Study). Br J Hematol (2019) 186(5):e123-6. doi: 10.1111/bjh.15964

69. Di Veroli A, Campagna A, De Muro M, Maurillo L, Trawinska MM, LeonettiCrescenzi S, et al. Deferasirox in the Treatment of Iron Overload During Myeloproliferative Neoplasms in Fibrotic Phase: Does Ferritin Decrement Matter? Leuk Res (2019) 76:65-9. doi: 10.1016/j.leukres.2018.11.012

70. Elli EM, Di Veroli A, Iurlo A, Carmosino I, Benevolo G, Abruzzese E, et al. Concomitant Treatment With Ruxolitinib and Deferasirox in the Management of Iron Overload in Patients With Myelofibrosis: A Multicenter Italian Experience. Blood (2019) 134(Suppl_1):839. doi: 10.1182/blood-2019-127488

71. Young NS, Calado RT, Scheinberg P. Current Concepts in the Pathophysiology and Treatment of Aplastic Anemia. Blood (2006) 108 (8):2509-19. doi: 10.1182/blood-2006-03-010777 
72. Jin P, Shi J, Li XX, Shao YQ, Nie N, Ge ML, et al. Study on Abnormal Iron Metabolism and Iron Overload in Patients With Aplastic Anemia. ZhonghuaXue Ye Xue Za Zhi (2013) 348(10):877-82. doi: 10.3760/ cma.j.issn.0253-2727.2013.10.011

73. Lee JW, Yoon SS, Shen ZX, Ganser A, Hsu HC, El-Ali A, et al. Hematologic Responses in Patients With Aplastic Anemia Treated With Deferasirox: A Post Hoc Analysis From the EPIC Study. Hematologica (2013) 98(7):1045-8. doi: 10.3324/hematol.2012.077669

74. Cancado R, Watman NP, Lobo C, Chona Z, Manzur F, Traina F, et al. Assessment of Liver and Cardiac Iron Overload Using MRI in Patients With Chronic Anemias in Latin American Countries: Results From ASIMILA Study. Hematology (2018) 23(9):676-82. doi: 10.1080/10245332.2018.1461292

75. Pawelec K, Salamonowicz M, Panasiuk A, Leszczynska E, Krawczuk-Rybak $\mathrm{M}$, Demkow U, et al. Influence of Iron Overload on Immunosuppressive Therapy in Children With Severe Aplastic Anemia. Adv Exp Med Biol (2015) 866:83-9. doi: 10.1007/5584_2015_148

76. Zhang X, Shi Y, Huang Y, Zhang G, He Y, Jiang E, et al. Serum Ferritin Is a Different Predictor From Transfusion History for Allogeneic Transplantation Outcome in Patients With Severe Aplastic Anemia. Hematology (2018) 23(5):291-8. doi: 10.1080/10245332.2017.1390929

77. Taher AT, Porter JB, Viprakasit V, Kattamis A, Chuncharunee S, Sutcharitchan P, et al. Defining Serum Ferritin Thresholds to Predict Clinically Relevant Liver Iron Concentrations for Guiding Deferasirox Therapy When MRI Is Unavailable in Patients With Non-TransfusionDependent Thalassaemia. Br J Haematol (2015) 168(2):284-90. doi: 10.1111/bjh.13119

78. Scheinberg P. Acquired Severe Aplastic Anaemia: How Medical Therapy Evolved in the 20th and 21st Centuries. Br J Haematol (2021) 194(6):954-69. doi: 10.1111/bjh.17403

79. Lee JW, Yoon SS, Shen ZX, Ganser A, Hsu HC, Habr D, et al. Iron Chelation Therapy With Deferasirox in Patients With Aplastic Anemia: A Subgroup Analysis of 116 Patients From the EPIC Trial. Blood (2010) 116(14):244854. doi: 10.1182/blood-2010-01-261289

80. Lee JW. Iron Chelation Therapy in the Myelodysplastic Syndromes and Aplastic Anemia: A Review of Experience in South Korea. Int $J$ Hematol (2008) 88(1):16-23. doi: 10.1007/s12185-008-0117-0

81. Messa E, Biale L, Castiglione A, Lunghi M, Bonferroni M, Salvi F, et al. Erythroid Response During Iron Chelation Therapy in a Cohort of Patients Affected by Hematologic Malignancies and Aplastic Anemia With Transfusion Requirement and Iron Overload: A FISM Italian Multicenter Retrospective Study. Leuk Lymphoma (2017) 58(11):2752-4. doi: 10.1080/ 10428194.2017.1312385

82. van Beers EJ, van Straaten S, Morton DH, Barcellini W, Eber SW, Glader B, et al. Prevalence and Management of Iron Overload in Pyruvate Kinase Deficiency: Report From the Pyruvate Kinase Deficiency Natural History Study. Hematologica (2019) 104(2):e51-3. doi: 10.3324/hematol.2018.196295

83. Porter JB, Lin KH, Beris P, Forni GL, Taher A, Habr D, et al. Response of Iron Overload to Deferasirox in Rare Transfusion-Dependent Anemias: Equivalent Effects on Serum Ferritin and Labile Plasma Iron for Haemolytic or Production Anemias. Eur J Hematol (2011) 87(4):338-48. doi: 10.1111/ j.1600-0609.2011.01660.x

84. Wesson LGJr. Renal Hemodynamics in Physiological States. In: Wesson LG, editor. Physiology of the Human Kidney. New York: Grune \& Stratton (1969). p. 98-100.

85. Ponticelli C, Musallam KM, Cianciulli P, Cappellini MD. Renal Complications in Transfusion-Dependent Beta Thalassaemia. Blood Rev (2010) 24(6):239-44. doi: 10.1016/j.blre.2010.08.004

86. Ige AO, Ongele FA, Adele BO, Emediong IE, Odetola AO, Adewoye EO. Pathophysiology of Iron Overload-Induced Renal Injury and Dysfunction: Roles of Renal Oxidative Stress and Systemic Inflammatory Mediators. Pathophysiology (2019) 26(2):175-80. doi: 10.1016/j.pathophys.2019.03.002

87. Demosthenous C, Vlachaki E, Apostolou C, Eleftheriou P, Kotsiafti A, Vetsiou E, et al. Beta-Thalassemia: Renal Complications and Mechanisms: A Narrative Review. Hematology (2019) 24(1):426-38. doi: 10.1080/ 16078454.2019.1599096

88. Mallat NS, Mallat SG, Musallam KM, Taher AT. Potential Mechanisms for Renal Damage in Beta-Thalassemia. J Nephrol (2013) 26(5):821-8. doi: $10.5301 /$ jn. 5000253
89. Cetin T, Oktenli C, Ozgurtas T, Yenicesu M, Sanisoglu SY, Oguz Y, et al. Renal Tubular Dysfunction in Beta-Thalassemia Minor. Am J Kidney Dis (2003) 42(6):1164-8. doi: 10.1053/j.ajkd.2003.08.016

90. Quinn CT, Johnson VL, Kim HY, Trachtenberg F, Vogiatzi MG, Kwiatkowski JL, et al. Renal Dysfunction in Patients With Thalassaemia. Br J Haematol (2011) 153(1):111-7. doi: 10.1111/j.1365-2141.2010.08477.x

91. Bakr A, Al-Tonbary Y, Osman G, El-Ashry R. Renal Complications of BetaThalassemia Major in Children. Am J Blood Res (2014) 4(1):1-6.

92. Hall AM, Bass P, Unwin RJ. Drug-Induced Renal Fanconi Syndrome. QJM (2014) 107(4):261-9. doi: 10.1093/qjmed/hct258

93. Dell'Orto VG, Bianchetti MG, Brazzola P. Hyperchloraemic Metabolic Acidosis Induced by the Iron Chelator Deferasirox: A Case Report and Review of the Literature. J Clin Pharm Ther (2013) 38(6):526-7. doi: 10.1111/jcpt.12095

94. Cappellini MD, Cohen A, Piga A, Bejaoui M, Perrotta S, Agaoglu L, et al. A Phase 3 Study of Deferasirox (ICL670), a Once-Daily Oral Iron Chelator, in Patients With Beta-Thalassemia. Blood (2006) 107(9):3455-62. doi: 10.1182/ blood-2005-08-3430

95. Cappellini MD, Taher A. Deferasirox (Exjade) for the Treatment of Iron Overload. Acta Hematol (2009) 122(2-3):165-73. doi: 10.1159/000243801

96. Cappellini MD, Porter J, El-Beshlawy A, Li CK, Seymour JF, Elalfy M, et al. Tailoring Iron Chelation by Iron Intake and Serum Ferritin: The Prospective EPIC Study of Deferasirox in 1744 Patients With Transfusion-Dependent Anemias. Hematologica (2010) 95(4):557-66. doi: 10.3324/hematol.2009.014696

97. Piga A, Fracchia S, Lai ME, Cappellini MD, Hirschberg R, Habr D, et al. Deferasirox Effect on Renal Haemodynamic Parameters in Patients With Transfusion-Dependent Beta Thalassaemia. Br J Hematol (2015) 168 (6):882-90. doi: 10.1111/bjh.13217

98. Al-Khabori M, Bhandari S, Al-Rasadi K, Mevada S, Al-Dhuhli H, Al-Kemyani N, et al. Correlation of Iron Overload and Glomerular Filtration Rate Estimated by Cystatin C in Patients With Beta-Thalassemia Major. Hemoglobin (2014) 38 (5):365-8. doi: 10.3109/03630269.2014.944314

99. Brewster UC, Perazella MA. Acute Kidney Injury Following Proton Pump Inhibitor Therapy. Kidney Int (2007) 71(6):589-93. doi: 10.1038/sj.ki.5002038

100. Esposito AJ, Murphy RC, Toukatly MN, Amro OW, Kestenbaum BR, Najafian B. Acute Kidney Injury in Allopurinol-Induced DRESS Syndrome: A Case Report of Concurrent Tubulointerstitial Nephritis and Kidney-Limited Necrotizing Vasculitis. Clin Nephrol (2017) 87(6):316-9. doi: $10.5414 / \mathrm{CN} 108966$

101. Kattamis A, Aydinok Y, Taher A. Optimising Management of Deferasirox Therapy for Patients With Transfusion-Dependent Thalassaemia and Lower-Risk Myelodysplastic Syndromes. Eur J Haematol (2018) 101 (3):272-82. doi: 10.1111/ejh.13111

102. Saliba AN, El Rassi F, Taher AT. Clinical Monitoring and Management of Complications Related to Chelation Therapy in Patients With $\beta$-Thalassemia. Expert Rev Hematol (2016) 9(2):151-68. doi: 10.1586/17474086.2016.1126176

103. Zhang Y, Xiao C, Li J, Song LX, Zhao YS, Han S, et al. Comparative Study on Iron Content Detection by Energy Spectral CT and MRI in MDS Patients. Front Oncol (2021) 11:646946. doi: 10.3389/fonc.2021.646946

104. Mantovani LF, Santos FPS, Perini GF, Nascimento CMB, Silva LP, Wroclawski CK, et al. Hepatic and Cardiac and Iron Overload Detected by $\mathrm{T}^{*}$ Magnetic Resonance (MRI) in Patients With Myelodisplastic Syndrome: A Cross-Sectional Study. Leuk Res (2019) 76:53-7. doi: 10.1016/j.leukres.2018.12.001

105. Angelucci E, Urru SA, Pilo F, Piperno A. Myelodysplastic Syndromes and Iron Chelation Therapy. Mediterr J Hematol Infect Dis (2017) 9(1):e2017021. doi: 10.4084/MJHID.2017.021

106. Pepe A, Rizzo M, Galimberti S, Baratè C, Oliva EN, Arcioni F, et al. Prospective Cardiac Magnetic Resonance Imaging Survey in Myelodysplastic Syndrome Patients: Insights From an Italian Network. Ann Hematol (2021) 100(5):1139-47. doi: 10.1007/s00277-021-04495-y

107. Tanaka C. Clinical Pharmacology of Deferasirox. Clin Pharmacokinet (2014) 53(8):679-94. doi: 10.1007/s40262-014-0151-4

108. Lee JW, Kang HJ, Choi JY, Kim NH, Jang MK, Yeo CW, et al. Pharmacogenetic Study of Deferasirox, an Iron Chelating Agent. PloS One (2013) 8(5):e64114. doi: 10.1371/journal.pone.0064114

109. Cusato J, Allegra S, Massano D, De Francia S, Piga A, D’Avolio A. Influence of Single-Nucleotide Polymorphisms on Deferasirox C Trough Levels and Effectiveness. Pharmacogenom J (2015) 15(3):263-71. doi: 10.1038/tpj.2014.65 
110. Li N, Chen Q, Gu J, Li S, Zhao G, Wang W, et al. Synergistic Inhibitory Effects of Deferasirox in Combination With Decitabine on Leukemia Cell Lines SKM-1, THP-1, and K-562. Oncotarget (2017) 8(22):36517-30. doi: 10.18632/oncotarget.16583

111. Choi JH, Kim JS, Won YW, Uhm J, Park BB, Lee YY. The Potential of Deferasirox as a Novel Therapeutic Modality in Gastric Cancer. World J Surg Oncol (2016) 14:77. doi: 10.1186/s12957-016-0829-1

112. Sechaud R, Robeva A, Belleli R, Balez S. Absence of an Effect of a Single-Dose Deferasirox on the Steady-State Pharmacokinetics of Digoxin. Int J Clin Pharmacol Ther (2008) 46(10):519-26. doi: 10.5414/cpp46519

113. Vlachodimitropoulou E, Chen YL, Garbowski M, Koonyosying P, Psaila B, Sola-Visner M, et al. Eltrombopag: A Powerful Chelator of Cellular or Extracellular Iron(III) Alone or Combined With a Second Chelator. Blood (2017) 130(17):1923-33. doi: 10.1182/blood-2016-10-740241

114. Fattizzo B, Cavallaro F, Milesi G, Barcellini W. Iron Mobilization in a Real Life Cohort of Aplastic Anemia Patients Treated With Eltrombopag. Am J Hematol (2019) 94(9):E237-9. doi: 10.1002/ajh.25550

Conflict of Interest: GP has received honoraria and/or served on the scientific advisory boards for Abbvie, Amgen, AOP, AstraZeneca, BMS Celgene, Janssen, and Novartis. WB: Consultant Novartis. EE: Participation to advisory board Novartis. CF: Novartis: advisory committees, speaker fees; Celgene: research funding, advisory committees, speaker fees; Takeda: consultancy. PM has received honoraria and/or served on the scientific advisory boards for Celgene, Janssen, Takeda, Bristol-Myers Squibb, Amgen, Novartis, Gilead, Jazz, Sanofi, Abbvie, Incyte, and Glaxo-Smith-Kline.

The remaining authors declare that the research was conducted in the absence of any commercial or financial relationships that could be construed as a potential conflict of interest.

Publisher's Note: All claims expressed in this article are solely those of the authors and do not necessarily represent those of their affiliated organizations, or those of the publisher, the editors and the reviewers. Any product that may be evaluated in this article, or claim that may be made by its manufacturer, is not guaranteed or endorsed by the publisher.

Copyright (c) 2021 Palumbo, Galimberti, Barcellini, Cilloni, Di Renzo, Elli, Finelli, Maurillo, Ricco, Musto, Russo and Latagliata. This is an open-access article distributed under the terms of the Creative Commons Attribution License (CC BY). The use, distribution or reproduction in other forums is permitted, provided the original author(s) and the copyright owner(s) are credited and that the original publication in this journal is cited, in accordance with accepted academic practice. No use, distribution or reproduction is permitted which does not comply with these terms. 